\title{
Dual-Action Pesticide Carrier That Continuously Induces Plant Resistance, Enhances Plant Anti-Tobacco Mosaic Virus Activity, and Promotes Plant Growth
}

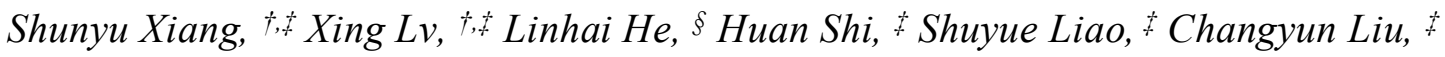
Qianqiao Huang, *Xinyu Li, * Xiaoting He, *Haitao Chen, " Daibin Wang, " and Xianchao Sun*,*

$\$$ College of Plant Protection and $\S$ School of Chemistry and Chemical Engineering, Southwest University, Chongqing 400715, People's Republic of China

// Chongqing Tobacco Science Research Institute, Chongqing, 400715, People's Republic of China

* Correspondence: Xianchao Sun Current address: College of Plant Protection, Southwest University, Beibei, Chongqing 400715, China. Email: sunxianchao@163.com

$\dagger$ The authors contributed equally to this work 


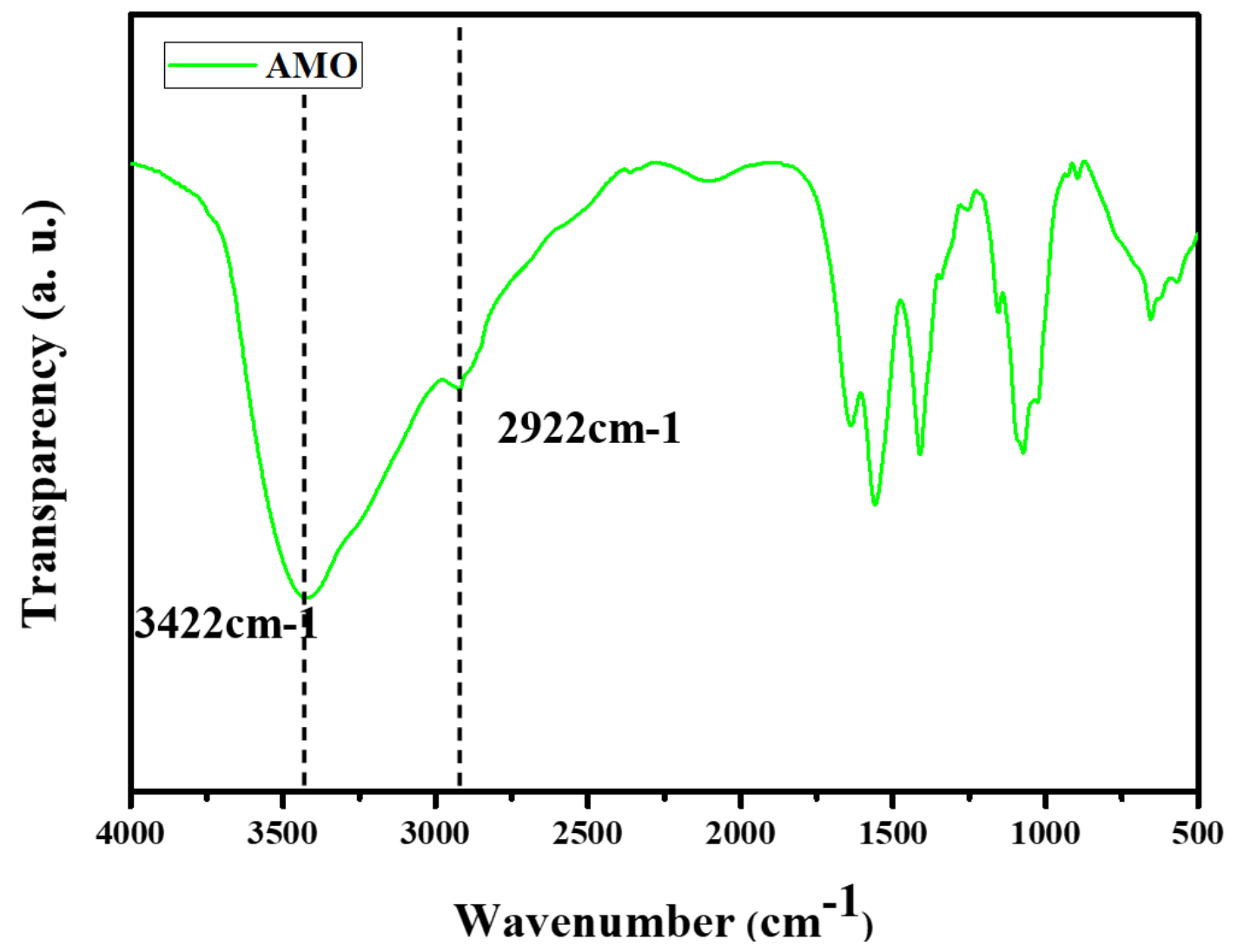

Figure S-1: FTIR spectra of amino-oligosaccharide 


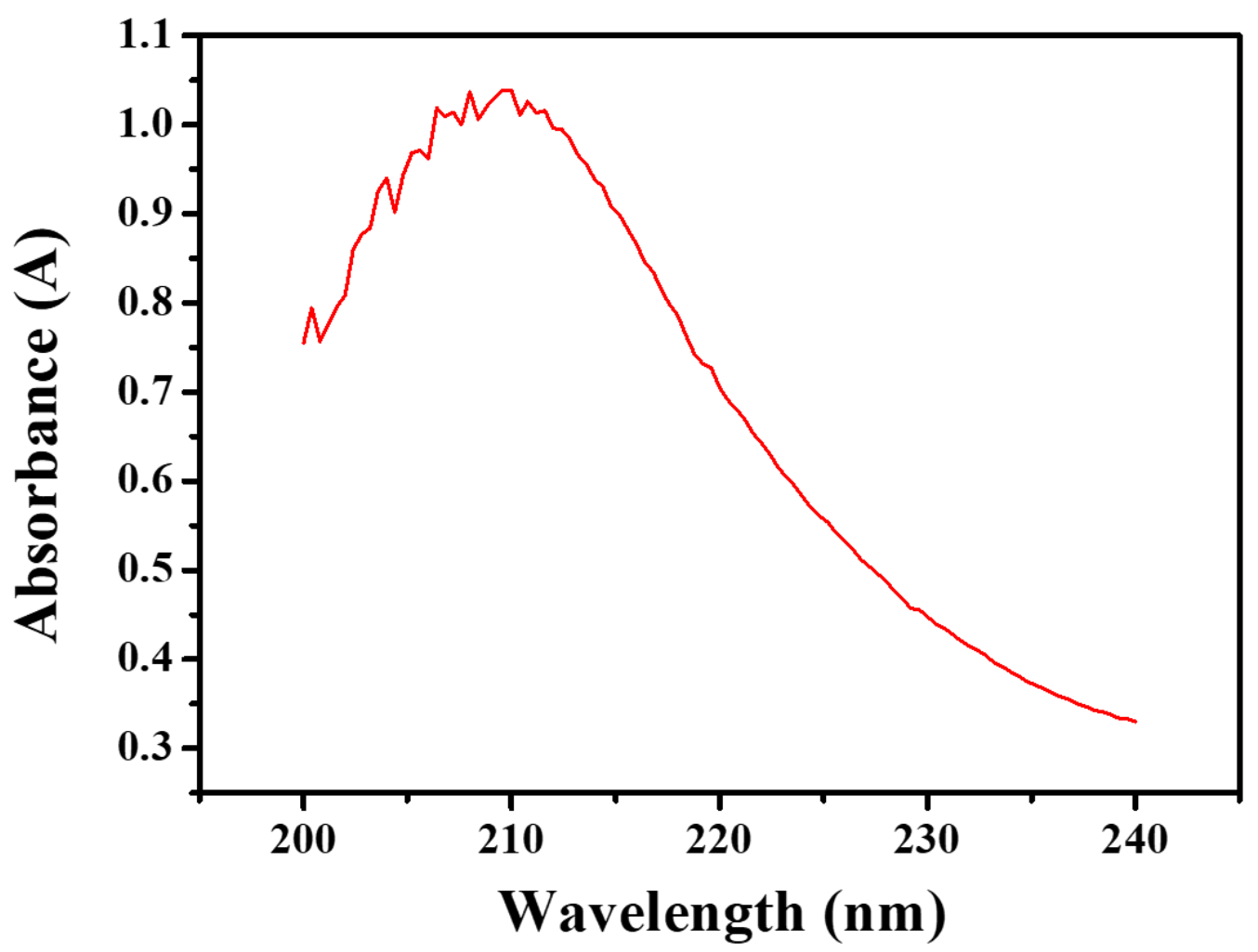

Figure S-2: Ultraviolet spectrum of lentinan 


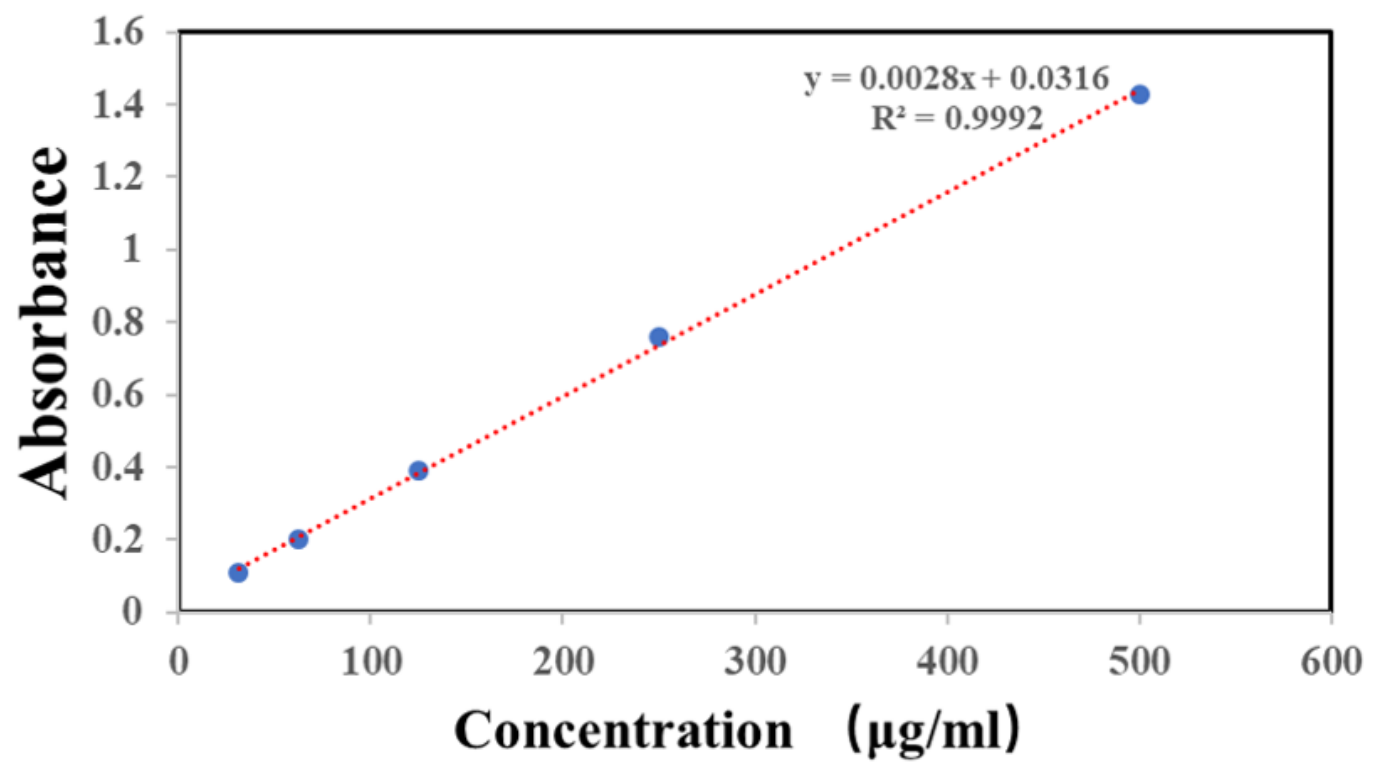

Figure S-3: Standard curve of lentinan, regression line $\mathrm{Y}=0.0028 \mathrm{X}+0.0316$ $\left(R^{2}=0.9992\right)$ 


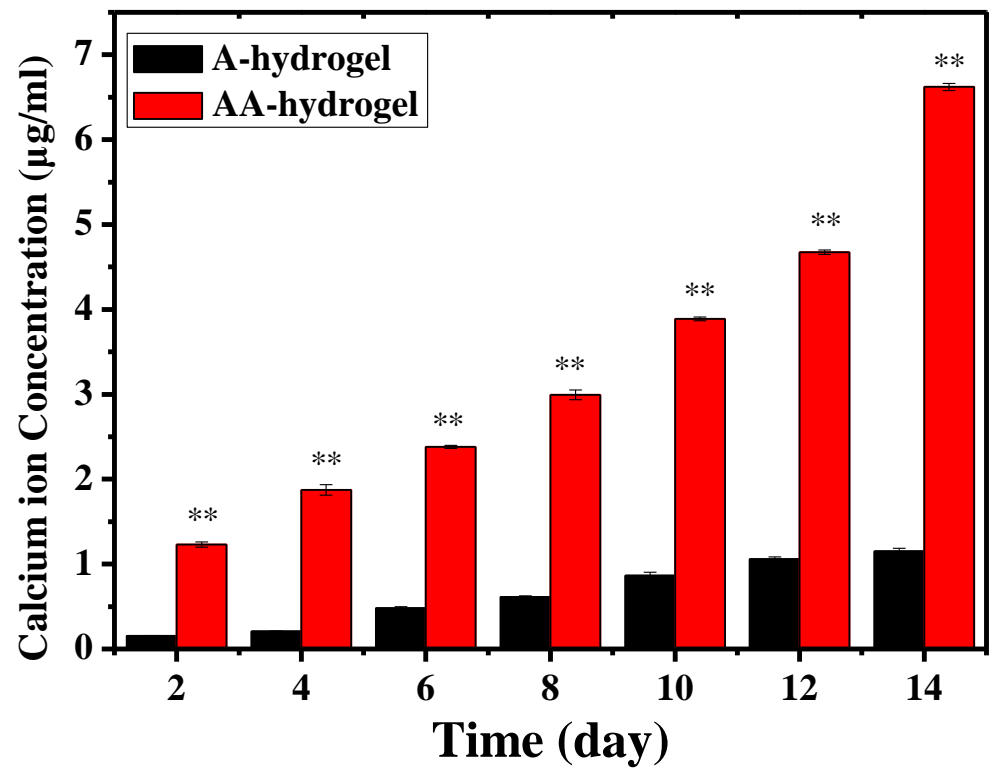

Figure S-4: A-hydrogel and AA-hydrogel calcium ion release statistics.

Table S-1: The $\mathrm{Ca}^{2+}$ cumulative release amount of ALA-hydrogel at different $\mathrm{Na}^{+}$ concentrations solution within 14 days

\begin{tabular}{cc}
\hline $\mathrm{NaCl}(\mathrm{M})$ & $\mathrm{Ca}^{2+}(\mu \mathrm{g} / \mathrm{ml})$ \\
\hline 0 & $7.29 \pm 0.102 \mathrm{a}$ \\
0.1 & $13.78 \pm 0.104 \mathrm{~b}$ \\
0.2 & $17.61 \pm 0.171 \mathrm{c}$ \\
0.4 & $21.09 \pm 0.098 \mathrm{~d}$ \\
0.8 & $23.42 \pm 0.076 \mathrm{e}$ \\
\hline
\end{tabular}


